\title{
Cerebroumbilical doppler ratio in pregnancy induced hypertension and its prediction for adverse perinatal outcome
}

\author{
Meena Bhati Salvi* \\ Department of Obstetrics and Gynecology, Prime Medical Center, Sharjan, Attached with Prime Hospital, Dubai, UAE \\ Received: 02 October 2019 \\ Accepted: 06 November 2019 \\ *Correspondence: \\ Dr. Meena Bhati Salvi, \\ E-mail: meenabhati2007@gmail.com \\ Copyright: (C) the author(s), publisher and licensee Medip Academy. This is an open-access article distributed under \\ the terms of the Creative Commons Attribution Non-Commercial License, which permits unrestricted non-commercial \\ use, distribution, and reproduction in any medium, provided the original work is properly cited.
}

\begin{abstract}
Background: To compare the changes in pulsatility index (PI) values of fetal middle cerebral artery (MCA), umbilical artery (UA) and ratio of PI of MCA and UA (cerebroumbilical ratio, C/U ratio) in normal pregnancies with pregnancy induced hypertension $(\mathrm{PIH})$ and to evaluate their usefulness for predicting adverse perinatal outcome.

Methods: This was a prospective comparative study carried out over a period of 1 year on total 140 patients between 30-40 weeks of gestation. Study group comprised of 70 patients with PIH. The control group comprised of 70 patients with normal BP. Both the groups were followed by doppler ultrasound and the UA PI, the MCA PI and the C/U ratio were measured. The results of the last doppler ultrasound before delivery were considered in the correlation with various adverse perinatal outcome. Sensitivity, specificity, positive predictive value, negative predictive value and diagnostic accuracy of MCA PI and UA PI and C/U ratio were calculated and compared for predicting adverse perinatal outcome.

Results: Abnormal C/U ratio was more common in PIH group (42.85\%) than control group (5.71\%). In the study group, $83.33 \%$ patients of abnormal $\mathrm{C} / \mathrm{U}$ ratio showed adverse perinatal outcome. $\mathrm{C} / \mathrm{U}$ ratio had highest sensitivity $(75.75 \%)$, negative predictive value $(80 \%)$ and diagnostic accuracy $(81.42 \%)$ compared to MCA PI and UA PI for predicting adverse perinatal outcome in PIH women.

Conclusions: Incidence of adverse perinatal outcome was more common with abnormal $\mathrm{C} / \mathrm{U}$ ratio. $\mathrm{C} / \mathrm{U}$ ratio is better predictor for adverse perinatal outcome in PIH women than individual MCA PI and UA PI.
\end{abstract}

Keywords: Cerebroumbilical ratio, Doppler ultrasound, Perinatal outcome, Pregnancy induced hypertension, Pulsatility index

\section{INTRODUCTION}

Pregnancy induced hypertension is associated with increased maternal and perinatal morbidity and mortality. It accounts for a total of $7-10 \%$ of perinatal mortality in developed countries and $20 \%$ in developing countries. The perinatal mortality is $5 \%$ in mild $\mathrm{PIH}$ and $15-25 \%$ in severe PIH. ${ }^{1}$ Blood studies by colour doppler ultrasound for evaluation of uteroplacental and fetoplacental circulation is one of the most recent advancement of modern obstetrics. ${ }^{2}$ Umbilical doppler studies have been shown to be of value in the management of high fetal risk pregnancies. ${ }^{3}$ Knowledge gained from the use of doppler velocimetry of the umbilical artery can distinguish between fetus that can safely be managed conservatively from the fetus really at risk of perinatal morbidity or mortality who is likely to benefit from earlier delivery, thus having a beneficial role in the management of high risk pregnancies. ${ }^{4}$

Increased blood supply to the fetal brain is one of the compensatory mechanisms in cases of decreased 
placental blood flow. This might suggest that MCA blood flow alterations in the group of patients with a high risk for unfavourable pregnancy outcome can be identified 23 weeks prior to delivery. ${ }^{5}$

Several authors have reported better sensitivity of the MCA/ UA ratio compared with MCA indices alone. Singh B et al, found that before 34 weeks of gestation, $\mathrm{MCA} / \mathrm{UA}$ ratios were a better predictor of perinatal death and other unfavourable pregnancy outcomes than was the umbilical artery alone. ${ }^{6}$

Both abnormal umbilical doppler indices and cerebralumbilical ratio are strong predictors of IUGR and of adverse perinatal outcome in preeclampsia. The MCA PI alone is not a reliable indicator. The combination of umbilical and fetal cerebral doppler indices may increase the utility of doppler ultrasound in preeclamptic subjects. ${ }^{7}$

Objectives of this study were to compare the changes in PI values of fetal MCA, UA and ratio of PI of MCA and $\mathrm{UA}(\mathrm{C} / \mathrm{U}$ ratio) in normal versus $\mathrm{PIH}$ pregnancies in the third trimester. And to evaluate their usefulness for predicting adverse perinatal outcome.

\section{METHODS}

This was a prospective comparative study carried out in the department of obstetrics and gynecology, J.L.N. Medical College and Zanana Hospital, Ajmer (Rajasthan), from June 2007 to May 2008. Informed consents were obtained from the patients. A total of 140 cases were selected between 30-40 weeks of gestation. The study group was comprised of 70 patients which was clinically diagnosed PIH $(\mathrm{BP}>140 / 90)$. The control group was comprised of 70 patients which was normotensive. Both the groups were having vertex presentation and singleton pregnancy. Patients with risk factors other than PIH i.e. multiple gestation, chronic hypertension, chronic renal disease, diabetes mellitus, secondary hypertension due to SLE were excluded from the study.

Gestational age determination was done by last menstrual period or first trimester scan. Both the groups were subjected to serial doppler assessment of umbilical and middle cerebral artery. The UA PI and the MCA PI were measured and $\mathrm{C} / \mathrm{U}$ ratio was calculated from PI of MCA divided by PI of UA.

We used reference value of 1.08 as single cut off value for prediction of adverse perinatal outcome according to Gramellini et al. ${ }^{8}$ Below this cut off value $\mathrm{C} / \mathrm{U}$ ratio was considered abnormal. The UA PI were considered abnormal when it was more than the reference values of corresponding gestational age and the MCA PI were considered abnormal when it was below the reference values of MCA PI in different gestational age as given by Saxena et al. ${ }^{2}$
The pregnancies were followed-up and the results of the last Doppler reading before delivery were considered in the subsequent correlation with perinatal outcome. The various perinatal outcome were emergency caesarean for foetal distress, intrauterine death, prematurity, apgar score $<7$ at 5 minute, birth weight less than 10th percentile, admission to NICU for more than 8 days. An adverse outcome was defined as the presence of one or more of the above-mentioned indicators.

\section{Statistical analysis}

The information collected was analysed using the statistical package for the social sciences software (SPSS) version 20.0. The data was represented as frequency or percentage. Sensitivity, specificity, PPV, NPV and diagnostic accuracy of MCA PI and UA PI and their ratio were calculated for predicting adverse perinatal outcome.

\section{RESULTS}

A total of 140 women were recruited for the study. PIH was more common in primigravida than multigravida and more frequent in age group of 21-25 years. The mean age in hypertensive was 25.75 years and in normotensive was 25.42 years and mean gestational age at delivery was 36.07 weeks and 37.35 weeks respectively. In $\mathrm{PIH}$ women a greater number of fetuses had lower birth weight than normal. Mean birth weight in study group was $2.37 \mathrm{~kg}$ and in control group was $2.7 \mathrm{~kg}$ (Table 1).

Table 1: Main characteristics of control and study group.

\begin{tabular}{|c|c|c|}
\hline Characteristics & $\begin{array}{l}\text { Control group } \\
(\mathrm{n}=70)\end{array}$ & $\begin{array}{l}\text { Study group } \\
(\mathbf{n}=\mathbf{7 0})\end{array}$ \\
\hline \multicolumn{3}{|l|}{ Parity } \\
\hline Primi & 38 & 42 \\
\hline Multi & 32 & 28 \\
\hline \multicolumn{3}{|c|}{ Maternal age (years) } \\
\hline$<20$ & 8 & 7 \\
\hline $21-25$ & 31 & 28 \\
\hline $26-30$ & 19 & 23 \\
\hline $31-35$ & 8 & 8 \\
\hline$>35$ & 4 & 4 \\
\hline \multicolumn{3}{|c|}{ Gestational age at birth } \\
\hline 30-35 weeks & 10 & 20 \\
\hline 36-38 weeks & 20 & 30 \\
\hline$>38$ weeks & 40 & 20 \\
\hline \multicolumn{3}{|c|}{ Birth weight (grams) } \\
\hline 30-35 weeks & 2.3 & 2.2 \\
\hline 36-38 weeks & 2.7 & 2.4 \\
\hline$>38$ weeks & 2.8 & 2.5 \\
\hline
\end{tabular}

In PIH group UA PI was more abnormal (28.57\%) than the control group $(4.28 \%)$. MCA PI was also more abnormal $(32.85 \%)$ in PIH group than the control group $(1.42 \%)$ (Table 2,3$)$. In study group a greater number of 
patients $(42.85 \%)$ had an abnormal $\mathrm{C} / \mathrm{U}$ ratio than the

control group $(5.71 \%)$ (Table 4$)$.

Table 2: Distribution of cases according to UA PI in control and study group.

\begin{tabular}{|lllll|}
\hline Indices & Control group (70) & & Study group ( 70) & Abnormal \\
\cline { 2 - 4 } & Normal & Abnormal & Normal & $20(28.57 \%)$ \\
\hline UA PI & $67(95.7 \%)$ & $3(4.28 \%)$ & $50(71.42 \%)$ & 20 \\
\hline
\end{tabular}

Table 3: Distribution of cases according to MCA PI in control and study group.

\begin{tabular}{|lllll|}
\hline Indices & Control group (70) & \multicolumn{3}{l|}{ Study group (70) } \\
\cline { 2 - 4 } & Normal & Abnormal & Normal & Abnormal \\
\hline MCA PI & $69(98.57 \%)$ & $1(1.42 \%)$ & $47(67.14 \%)$ & $23(32.85 \%)$ \\
\hline
\end{tabular}

Table 4: Distribution of cases according to C/U doppler ratio (MCA PI/UA PI) in control and study group.

\begin{tabular}{|lllll|}
\hline Doppler indices & Control group (70) & & Study group (70) & Abnormal \\
\cline { 2 - 5 } & Normal & Abnormal & Normal & $30(42.85 \%)$ \\
\hline C/U ratio & $66(94.28 \%)$ & $4(5.71 \%)$ & $40(57.14 \%)$ & 3 \\
\hline
\end{tabular}

Table 5: Distribution of cases according to doppler indices.

\begin{tabular}{|lllllll|}
\hline & UA PI & & MCA PI & & \multicolumn{2}{c|}{ MCA / UA PI } \\
& Normal & Abnormal & Normal & Abnormal & Normal & Abnormal \\
\hline Study group (70) & $50(71.42 \%)$ & $20(28.57 \%)$ & $47(67.14 \%)$ & $23(32.85 \%)$ & $40(57.14 \%)$ & $30(42.85 \%)$ \\
\hline Control group (70) & $67(95.7 \%)$ & $3(4.28 \%)$ & $69(98.57 \%)$ & $1(1.42 \%)$ & $66(94.28 \%)$ & $4(5.71 \%)$ \\
\hline
\end{tabular}

Table 6: Perinatal outcome of PIH women (study group) according to last doppler indices.

\begin{tabular}{|lllllll|}
\hline & UA PI & & MCA PI & \multicolumn{2}{l|}{ MCA UA PI } \\
\hline & Normal (50) & Abnormal (20) & Normal (47) & Abnormal (23) & Normal (40) & Abnormal (30) \\
\hline Adverse perinatal outcome & 12 & 18 & 14 & 13 & 8 & 25 \\
\hline$\%$ & 24 & 90 & 29.78 & 56.52 & 20 & 83.33 \\
\hline
\end{tabular}

Table 7: Indicators of adverse perinatal outcome in study group according to doppler indices.

\begin{tabular}{|c|c|c|c|c|c|c|}
\hline \multirow[b]{2}{*}{ Outcome indicators } & \multicolumn{2}{|l|}{ UA PI } & \multicolumn{2}{|l|}{ MCA PI } & \multicolumn{2}{|c|}{ MCA/UA PI } \\
\hline & $\begin{array}{l}\text { Normal } \\
(\mathbf{5 0})\end{array}$ & $\begin{array}{l}\text { Abnormal } \\
\text { (20) }\end{array}$ & $\begin{array}{l}\text { Normal } \\
\text { (47) }\end{array}$ & $\begin{array}{l}\text { Abnormal } \\
(23)\end{array}$ & $\begin{array}{l}\text { Normal } \\
(40)\end{array}$ & $\begin{array}{l}\text { Abnormal } \\
\text { (30) }\end{array}$ \\
\hline Emergency cesarean & $10(20 \%)$ & $12(60 \%)$ & $11(23.4 \%)$ & $12(52.08 \%)$ & $7(17.5 \%)$ & $20(66.6 \%)$ \\
\hline Apgar $<7$ at 5 minute & $4(8 \%)$ & $12(60 \%)$ & $8(16.96 \%)$ & $6(26.04 \%)$ & $3(7.5 \%)$ & $18(60 \%)$ \\
\hline Stay in NICU>7 days & $8(16 \%)$ & $12(60 \%)$ & $13(27.56 \%)$ & $10(43.4 \%)$ & $4(10 \%)$ & $18(60 \%)$ \\
\hline Perinatal death & $1(2 \%)$ & $4(20 \%)$ & $5(10.6 \%)$ & $5(21.7 \%)$ & $4(10 \%)$ & $7(23.33 \%)$ \\
\hline IUGR & $9(18 \%)$ & $15(75 \%)$ & $12(25.44 \%)$ & $11(47.74 \%)$ & $6(15 \%)$ & $25(83.25 \%)$ \\
\hline
\end{tabular}

Table 8: Accuracy of various doppler indices in predicting adverse perinatal outcome.

\begin{tabular}{|c|c|c|c|c|c|}
\hline$\% \mathrm{n}$ & Sensitivity & Specificity & $\begin{array}{l}\text { Positive predictive } \\
\text { value }\end{array}$ & $\begin{array}{l}\text { Negative predictive } \\
\text { value }\end{array}$ & $\begin{array}{l}\text { Diagnostic } \\
\text { accuracy }\end{array}$ \\
\hline UA PI & $60 \%$ & $95 \%$ & $90 \%$ & $76 \%$ & $80 \%$ \\
\hline MCA PI & $48.14 \%$ & $76.74 \%$ & $56.52 \%$ & $70.21 \%$ & $65.71 \%$ \\
\hline MCAPI/UAPI & $75.75 \%$ & $86.48 \%$ & $83.33 \%$ & $80 \%$ & $81.42 \%$ \\
\hline
\end{tabular}

Abnormal doppler indices were found in $28.57 \%$ UA PI, $32.85 \% \mathrm{MCA} \mathrm{PI}$ and $42.85 \% \mathrm{C} / \mathrm{U}$ ratio in study group while in control group were $4.28 \%, 1.42 \%$ and $5.71 \%$ respectively (Table 5). In the study group, out of 50 patients who had normal UA PI, only 12 patients had adverse perinatal outcome while it was 18 out of 20 in 
abnormal UA PI patients. Out of 47 patients of normal MCA PI, 14 patients had adverse perinatal outcome and out of 23 patients of abnormal MCA PI, 13 patients had adverse perinatal outcome. 8 out of 40 patients of normal $\mathrm{C} / \mathrm{U}$ ratio and 25 out of 30 patients of abnormal $\mathrm{C} / \mathrm{U}$ ratio were affected by adverse perinatal outcome (Table 6).

Table 9: Comparison of UA PI in predicting adverse perinatal outcome.

\begin{tabular}{|c|c|c|c|c|c|}
\hline Study & Sensitivity & Specificity & $\begin{array}{l}\text { Positive predictive } \\
\text { value }\end{array}$ & $\begin{array}{l}\text { Negative predictive } \\
\text { value }\end{array}$ & $\begin{array}{l}\text { Diagnostic } \\
\text { accuracy }\end{array}$ \\
\hline Gramellini et al & $64 \%$ & $90.7 \%$ & $72.7 \%$ & $86.7 \%$ & $83.3 \%$ \\
\hline Lakhkar et al & $58 \%$ & $56.5 \%$ & $35 \%$ & $86.8 \%$ & - \\
\hline Ozeren et al & $69 \%$ & $97 \%$ & $95 \%$ & $81 \%$ & $85 \%$ \\
\hline Smitha et al & $90.26 \%$ & $80.57 \%$ & $82.24 \%$ & $88.35 \%$ & $84 \%$ \\
\hline Present study & $60 \%$ & $95 \%$ & $90 \%$ & $76 \%$ & $80 \%$ \\
\hline
\end{tabular}

Table 10: Comparison of MCA PI in predicting adverse perinatal outcome.

\begin{tabular}{|c|c|c|c|c|c|}
\hline Study & Sensitivity & Specificity & $\begin{array}{l}\text { Positive predictive } \\
\text { value }\end{array}$ & $\begin{array}{l}\text { Negative predictive } \\
\text { value }\end{array}$ & $\begin{array}{l}\text { Diagnostic } \\
\text { accuracy }\end{array}$ \\
\hline Gramellini et al & $24 \%$ & $100 \%$ & $100 \%$ & $77.3 \%$ & $78.8 \%$ \\
\hline Lakhkar et al & $66.6 \%$ & $71.7 \%$ & $47 \%$ & $90 \%$ & - \\
\hline Smitha et al & $86.24 \%$ & $50.63 \%$ & $62.23 \%$ & $80.24 \%$ & $64 \%$ \\
\hline Present study & $48.14 \%$ & $76.74 \%$ & $56.52 \%$ & $70.21 \%$ & $65.71 \%$ \\
\hline
\end{tabular}

Table 11: Comparison of MCA/UA PI (C/U ratio) in predicting adverse perinatal outcome.

\begin{tabular}{|c|c|c|c|c|c|}
\hline Study & Sensitivity & Specificity & $\begin{array}{l}\text { Positive predictive } \\
\text { value }\end{array}$ & $\begin{array}{l}\text { Negative predictive } \\
\text { value }\end{array}$ & $\begin{array}{l}\text { Diagnostic } \\
\text { accuracy }\end{array}$ \\
\hline Gramellini et al & $68 \%$ & $98.4 \%$ & $94.4 \%$ & $88 \%$ & $90 \%$ \\
\hline Lakhkar et al & $66.6 \%$ & $73.9 \%$ & $40 \%$ & $89.4 \%$ & - \\
\hline Ozeren et al & $81 \%$ & $89 \%$ & $84 \%$ & $86 \%$ & $85 \%$ \\
\hline Smitha et al & $94.42 \%$ & $82.65 \%$ & $86.42 \%$ & $96.41 \%$ & $90 \%$ \\
\hline Present study & $75.75 \%$ & $86.48 \%$ & $83.33 \%$ & $80 \%$ & $81.42 \%$ \\
\hline
\end{tabular}

In the study group fetuses with abnormal ratio were frequently delivered by caesarean section especially for fetal distress in $66.6 \%$. The perinates had lower birth weight percentile in $83.25 \%$ and had low apgar score in $60 \%$. Most of these neonates, i.e. $60 \%$ required admission in NICU and spent longer time there. Perinatal death was $23.33 \%$. In the normal ratio group less number of patients had adverse perinatal outcome (Table 7).

In the present study, the cerebroumbilical ratio (MCA/UA PI) had highest sensitivity (75.75\%), negative predictive value (80\%) and diagnostic accuracy (81.42\%) in predicting adverse perinatal outcome, compared to UA PI $(60 \%, 76 \%, 80 \%)$ and MCA PI $(48.14 \%, 70.21 \%$, $65.71 \%$ ) respectively (Table 8 ).

The present study findings in prediction of adverse perinatal outcome are comparable with studies done by Gramellini et al, Lakhkar et al, Ozeren et al and Smitha et al (Table 9, 10, 11). ${ }^{7-10}$ Gramellini et al and Smitha et al, concluded that ratio is having high sensitivity, negative predictive value and diagnostic accuracy than UA PI and MCA PI. ${ }^{8,10}$ Lakhkar et al, in their study found that ratio had highest sensitivity and specificity.9 In study done by Ozeren et al. higher sensitivity and negative predictive value was found with $\mathrm{C} / \mathrm{U}$ ratio (Table 9,10,11). ${ }^{7}$

\section{DISCUSSION}

The results of present study showed that prevalence of $\mathrm{PIH}$ was more common in primigravida than multigravida which is similar to other studies also, Radhika $\mathrm{P}$ et al, (61.8\%) and Lakhkar BN et al $(60.3 \%){ }^{9}{ }^{911} \mathrm{PIH}$ was more frequent in age group of 21-25 years with mean age 25.75 years which is comparable to others authors Campbell and Pattinson. ${ }^{12,13}$ Mean gestational age at delivery was slight less (36.0 weeks) in PIH women than control group (37.35 weeks) because of early induction of labour in them to prevent adverse outcome or emergency caesarean as indicated by abnormal doppler indices. In study of Shah Nehal et al. mean gestational age at birth in PIH women also slight earlier than normotensive women. ${ }^{14}$ The average birth weight in study group was $2.3 \mathrm{~kg}$ and in control group was $2.7 \mathrm{~kg}$ reflecting lower birth weight in PIH women due to fetal compromisation, increase placental 
resistance, less oxygenation causing intra uterine growth retardation. In study done by Ebrashy et al, and Lakhkar BN et al, average birth weight was $1.87 \mathrm{~kg}$ and $1.79 \mathrm{~kg}$ respectively in $\mathrm{PIH}$ women which was lower than control group..$^{9,15}$

In normal pregnancy there is reduction in values of doppler indices due to the invasion of cytotrophoblast into the spiral arteries leading to the loss of the musculature component, dilatation and uncoiling of these uteroplacental vessels. This results in progressive loss of vascular impedence and increase in end diastolic flow in later half of pregnancy. ${ }^{16}$ In pregnancies complicated by hypertension or fetal growth retardation this does not occur and therefore the Doppler indices are higher. ${ }^{17}$

In the studies of different authors UA PI decreases from 30-40 weeks in normotensive pregnancies as suggested by Pearce et al, Gramellini et al, Saxena et al, Thakur S et al. ${ }^{2,4,8,18}$ In present study PI of UA was raised (abnormal) in $28.57 \%$ in PIH women while only $4.28 \%$ in normotensive women. In PIH first there is decreased diastolic flow in the umbilical artery due to increase in the resistance. This raises the $\mathrm{S} / \mathrm{D}$ ratio, $\mathrm{PI}$ and $\mathrm{RI}$ of umbilical artery. As the placental insufficiency worsens, the diastolic flow decreases, then become absent, and later reverses. Some foetuses have decreased diastolic velocity that remains constant with advancing gestation and never become absent or reversed which may be due to a milder form of placental insufficiency. ${ }^{9}$

In the studies of different authors MCA PI decreased from 30-40 weeks in normotensive pregnancies as suggested by Pearce et al, Gramellini et al, Saxena et al, due to increase fetal perfusion. ${ }^{2,8,18}$ At the same time the values in hypertensive group will be lower than the normotensive group, suggesting decrease in impedance and increase in diastolic blood flow in the brain. Similar to this, in study group, $32.85 \%$ patients were having abnormal MCA PI that is lower than normal values. MCA doppler velocimetry identifies redistribution of blood to the brain called the brain sparing effect in case of fetal hypoxia. Astrom et al, reported that impaired uteroplacental circulation and imminent fetal asphyxia cause increase in the diastolic flow in the fetal middle cerebral artery. This leads to decrease in doppler indices. The brain sparing effect however, may be a transitory finding that disappears after development of cerebral oedema or severe hypoxia. ${ }^{19}$

Thus, doppler indices UA PI and MCA PI that reflect umbilical placental and cerebral vascular area can be useful for identifying fetuses with increased placental and /or decreased cerebral resistance. ${ }^{8}$

A $\mathrm{C} / \mathrm{U}$ ratio that reflects both Doppler indices, is more useful in the diagnosis of PIH and its perinatal outcome. Different authors like Pearce et al, Gramellini et al, Ebrashy et al, gave cut off value of ratio and concluded that this value is constant during last 10 weeks of pregnancy. ${ }^{8,15,18}$ Doppler index below this value is considered abnormal.

In present study there was more number of patients (42.85\%) had abnormal $\mathrm{C} / \mathrm{U}$ ratio in $\mathrm{PIH}$ women compare to $5.71 \%$ patients in normotensive women. Thus, on analysis of individual doppler indices and ratio that in study group $28.57 \%$ cases had abnormal UA PI, $32.85 \%$ cases had abnormal MCA PI, while $42.85 \%$ cases had abnormal $\mathrm{C} / \mathrm{U}$ ratio. In control group very less number of cases had these abnormal indices.

Some studies proved doppler indices as better predictor of adverse perinatal outcome while some studies proved that $\mathrm{C} / \mathrm{U}$ ratio is a better predictor for the adverse perinatal outcome for prediction of SGA foetuses than either vessels Doppler alone. ${ }^{10}$ In present study we found that adverse perinatal outcome in cases with abnormal UA PI was $90 \%$, with abnormal MCA PI was $56.52 \%$ and with abnormal ratio was $83.33 \%$ in study group. No adverse perinatal outcome was found in control group in present study.

In the analysis of adverse perinatal outcome in $\mathrm{PIH}$ women we found that women who had abnormal $\mathrm{C} / \mathrm{U}$ ratio were delivered by emergency caesarean $(66.6 \%)$ and had neonatal apgar $<7$ at 5 minute in $60 \%$, neonatal stay in NICU > 7 days in $60 \%$, perinatal death in $23.33 \%$ and intra uterine growth retardation of fetus in $83.25 \%$; which was more frequent than women who had abnormal UA PI or abnormal MCA PI alone. According to Gramellini et al, the best results were obtained when the $\mathrm{C} / \mathrm{U}$ ratio was used to predict adverse perinatal outcome as compared with the umbilical artery and middle cerebral artery. ${ }^{8}$ Maksheed et al, also suggested that the $\mathrm{C} / \mathrm{U}$ ratio is an effective predictive of neonatal outcome, and would be useful in identify fetuses at risk of morbidity and mortality. ${ }^{20}$

Lakhkar BN et al, also found that ratio of PI of MCA/UA is more sensitive than MCA PI alone in predicting adverse neonatal outcome. ${ }^{9}$ According to Arias et al, C/U ratio was more accurate than each of its components in the diagnosis of IUGR. This makes sense because the $\mathrm{C} / \mathrm{U}$ ratio will reflect not only the circulating insufficiency of the placenta manifested by alternating in the umbilical resistance index but also the adaptive changes resulting in modifications of middle cerebral resistance index. ${ }^{21}$ Thus our result was similar to other studies.

In present study, on individually calculating the PI of UA and MCA, the sensitivity was found to be $60 \%$ and $48.14 \%$ but for the ratio it was increased to $75.75 \%$. The diagnostic accuracy of $\mathrm{C} / \mathrm{U}$ ratio was found to be $81.42 \%$ followed by UAPI and MCA PI, $80 \%$ and $65.71 \%$. The $\mathrm{NPV}$ of C/U ratio was highest $(80 \%)$ followed by UA PI $(76 \%)$ and MCA PI $(70.21 \%)$. The specificity and PPV of ratio were $86.48 \%$ and $83.33 \%$ respectively which was lesser than UA PI $(95 \%, 90 \%)$. Overall it was found that 
$\mathrm{C} / \mathrm{U}$ ratio had better sensitivity $75.75 \%$, NPV $80 \%$ and diagnostic accuracy $81.42 \%$ than either MCA or UA PI indices in predicting poor neonatal outcome.

On comparison of sensitivity, NPV and diagnostic accuracy by different authors, we found that our study was more or less similar to other studies. Sensitivity of ratio was increased to $68 \%$ than individual indices in Gramellini et al, up to $66.6 \%$ in study done by Lakhkar et al, up to $81 \%$ in study done by Ozeren et al and up to $94.42 \%$ in study done by Smitha et al. ${ }^{7-10}$ In present study also sensitivity of $\mathrm{C} / \mathrm{U}$ ratio was increased to $75.75 \%$ than individual UA PI (60\%) and MCAPI (48.14\%) indices.

In our study NPV of C/U ratio was higher (80\%) than UA PI $(76 \%)$ and MCA PI $(70.21 \%)$ which is comparable to study done by Gramellini et al (88\%), Ozeren et al (86\%) and Smitha et al $(96.41 \%))^{7,6,10}$ In their study NPV of ratio was higher than UA PI and MCA PI. Our result for NPV was slightly different from Lakhkar et al, they found high NPV of MCA PI (90\%) than UA PI (86.8\%) and ratio $(89.4 \%)$. But in their study difference was very less between NPV value of MCA PI and ratio. ${ }^{9}$

The diagnostic accuracy in our study increased to $81.42 \%$ than either MCA or UA PI indices which was comparable to other studies. In study done by Gramellini et al, diagnostic accuracy of ratio was increased to $90 \%$ than individual values. ${ }^{8}$ Ozeren et al. found that diagnostic accuracy of $\mathrm{C} / \mathrm{U}$ ratio was same as UA PI (85\%) but not less than this. ${ }^{7}$ Smitha et al, in their study found that ratio had better diagnostic accuracy $(90 \%)$ than individual UA PI $(84 \%)$ and MCA PI (64\%) indices. ${ }^{10}$ Thus our study confirmed the previous findings of other authors in evaluating the usefulness of $\mathrm{C} / \mathrm{U}$ doppler ratio in predicting the adverse perinatal outcome.

\section{CONCLUSION}

In present study we found a strong correlation between $\mathrm{C} / \mathrm{U}$ ratio and perinatal outcome in $\mathrm{PIH}$ women. Considering highest sensitivity $(75.75 \%)$, negative predictive value $(80 \%)$ and diagnostic accuracy $(81.42 \%)$ than individual indices, our result suggested that $\mathrm{C} / \mathrm{U}$ ratio is better predictor than MCA PI and UA PI indices for adverse perinatal outcome in PIH women in third trimester.

Funding: No funding sources Conflict of interest: None declared

Ethical approval: Not required

\section{REFERENCES}

1. Ratnam S, Rao BK, Kumaran A. Reproductive health of women in india during the last. Obstet Gynaecol, 1992;1:54.

2. Saxena K, Haroon S, Rabbani T, Rana S. Blood flow studies in evaluation of fetal well being: a study of normal and hypertensive pregnancies. J Obstet Gynecol of Ind. 2001;51(5):64-74.

3. Trudinger BJ, Cook CM, Giles WB, Connelly A. Umbilical artery flow velocity waveforms in highrisk pregnancy. Randomized controlled trial. The Lancet. 1987;24.

4. Thakur S, Negi PC, Gupta T. Doppler waveform analysis of the umbilical artery in normal pregnancies (Normogram) at Shimla. J Obst Gyn India. 2001;51(3):43-7.

5. Simanaviciute D, Gudmundsson S. Fetal middle cerebral to uterine artery pulsatility index ratios in normal and preeclamptic pregnancies. Ultrasound Obstet Gynecol. 2006;28(6):794-801.

6. Singh B, Kovanci RO, Jeffres E, Oz A, Deren $\mathrm{U}$, Copel O, et al. The doppler cerebroplacental ratio and perinatal outcome in intrauterine growth restriction. Am J Obstet Gynecol. 1999;180:750-6.

7. Ozeren M, Dinc H, Ekmen U, Senekayli C, Aydemir V. Umbilical and middle cerebral artery Doppler indices in patients with preeclampsia. Eur J Obstet Gynecol Reprod Biol. 1999;82:11-6.

8. Gramellini D, Folli MC, Raboni S, Vadora E, Merialdi A. Cerebral umbilical Doppler ratio as a predictor of adverse perinatal outcome. Obstet Gynecol. 1992;79:416-20.

9. Lakhkar BN, Rajagopal KV, Gourisankar PT. Doppler prediction of adverse perinatal outcome in PIH and IUGR. Indian J Radiol Imag. 2006;16:10916.

10. Smitha K, Sowmya K, Malathi T. Study of Doppler waveforms in pregnancy induced hypertension and its correlation with perinatal outcome. Int J Reprod Contracept Obstet Gynecol. 2014:3(2):428-33.

11. Padmagirison R, Rai L. Fetal doppler versus NST as predictors of adverse perinatal outcome in severe preeclampsia and fetal growth restriction. J Obstet Gynecol. 2006;56:134-8.

12. Campbell, S, Diaz-Recasens, J, Griffin, D, CohenOverbeek, T, Pearce, J, Wilson, K, et al. Doppler technique for assessing utero-placental blood flow. Lancet. 1983;1:675-7.

13. Pattinson RC. Consultant, Karenn Orman Consultant, Hein J. Odendaal. The role of Doppler velocimetry in the management of high risk pregnancies. Br J Obstet Gynaecol. 1994;101:11420.

14. Shah NS, Maitra N, Verma RN, Desai VA. Umbilical and cerebral arterial flow velocity waveforms and neonatal outcome in high risk pregnancy, J Obstet Gynecol India. 2007;57(3):21620.

15. Ebrashy A, Azmy O, Ibrahim M, Waly M, Edris A. Middle cerebral/umbilical artery resistance index ratio as sensitive parameter for fetal well-being and neonatal outcome in patients with preeclampsia: case-control study. Croat Med J. 2005;46(5):821-5.

16. Harman C. Doppler ultrasound maternal applications: In Fleischer AC, Manning FA, Jeanty $\mathrm{P}$, Romero $\mathrm{R}$ eds. Sonography in Obstetrics and 
Gynaecology principles and practice. Connecticut. Appleton Lange. 1995:223-49.

17. Trudinger BJ, Giles WB, Cook CM. Uteroplacental blood flow velocity-time waveforms in normal and complicated pregnancy. $\mathrm{Br} \mathrm{J}$ Obstet Gynaecol. 1985;92(1):39-45.

18. Pearce JM, Campbell S, Cohen-Overbeek T, Hackett G, Hernandez J, Royston JP. References ranges and sources of variation for indices of pulsed Doppler flow velocity waveforms from the uteroplacental and fetal circulation. $\mathrm{Br} \quad \mathrm{J}$ Obstet Gynaecol. 1988;95(3):248-56.

19. Arström K, Eliasson A, Hareide JH, Marsal K. Fetal blood velocity waveforms in normal pregnancies. A longitudinal study. Acta Obstet Gynecol Scand. 1989;68(2):171-8.
20. Makhseed M, Jirous J, Ahmed MA, Viswanathan DL. Middle cerebral artery to umbilical artery resistance index ratio in the prediction of neonatal outcome. Int J Gynaecol Obstet. 2000;71:119-25.

21. Arias F. Accuracy of the middle-cerebral-toumbilical-artery resistance index ratio in the prediction of neonatal outcome in patients at high risk for fetal and neonatal complications. Am J Obstet Gynecol. 1994;171:1541-5.

Cite this article as: Salvi MB. Cerebroumbilical doppler ratio in pregnancy induced hypertension and its prediction for adverse perinatal outcome. Int $\mathbf{J}$ Reprod Contracept Obstet Gynecol 2019;8:49955001 . 